\title{
Pharmacology education for physicians: the shift from materia medica to pharmacology and the scientific paradigm in medicine at the University of Buenos Aires (Argentina)
}

\author{
Ines Mi Bignone, Ricardo Bolanos, Analia Sabbattini, Lucas Goldin, Estela B Quinones, Roberto \\ A Diez
}

Pharmacology, School of Medicine, UBA, Argentina

\section{Background}

For 3 centuries Argentina was a Spanish colony and no local training in pharmacology was available until the creation of the Protomedicato school in 1799. After independence (1816), medical studies were transferred to the new University of Buenos Aires, created in 1821. By then, training followed the Spanish standard and Materia Medica included a lot of traditional therapeutic procedures. By1900, a different perspective was easily detectable, with strong influence of European scientists. The aim of this research is to characterize that shift and the more modern emphasis on clinical pharmacology.

Methods

We searched textbooks, papers and thesis filed at the library of the schools of medicine, dentistry, pharmacy and veterinary medicine of the University of Buenos Aires, at the National Academy of Medicine and the Argentine Medical Association.

Results

Until the end of the XXth century, 16 full professors of pharmacology (initially, Materia Medica) teached pharmacology at our school. Prolonged periods allowed long-lasting personal imprint of some professors, such as Jos\&\#233; Fuentes Arguibel (1830-1839 and 1848-1852, under whom anesthesia use began in Buenos Aires), Pedro A. Mattos (1875-1888, an hygienist involved in the control of yellow fever in Buenos Aires), his disciple Justiniano A. Ledesma (1889-1918, strongly influenced by homeopathy). His successors, Jos\&\#233; Moreno (1919-1928) and Ignacio Ymaz (1929-1939), continued and reinforced by Mario Soto (1940-1952) and Manuel Litter (1973-1976) strongly changed the orientation. The name changed to pharmacology in 1933, though a scientific approach can be detected since de 1870 decade, reflecting the influence of contemporary European scientists. Interest in clinical pharmacology began with Moreno, who attempted to create a Clinical Pharmacology Section at the university hospital, hindered by his sudden death. His disciple Ymaz, succeed in creating such section. Early in the 70's the clinical pharmacology section disappeared and was re-created by Norberto A. Terragno (1982-1999) in 1994, before the CPT held in Buenos Aires (1996).

Conclusions

Science became an important part of pharmacology teaching in Buenos Aires by the end of the 19th century. Explicit interest in clinical pharmacology began in first half of the XXth century, with contradictory development until the end of the century. 